\title{
Herwig Wolfram, The Roman Empire and Its Germanic Peoples
}

Trad. de Thomas Dunlap. Berkeley -Los Angeles, University of California Press, 2005, $\mathrm{XX}+361 \mathrm{p}$.

Rémi Gounelle

\section{OpenEdition}

1 Journals

Édition électronique

URL : http://journals.openedition.org/assr/12233

DOI : $10.4000 /$ assr. 12233

ISSN : $1777-5825$

Éditeur

Éditions de l'EHESS

Édition imprimée

Date de publication : 1 décembre 2007

Pagination : 157-310

ISBN : 978-2-7132-2145-3

ISSN : 0335-5985

Référence électronique

Rémi Gounelle, "Herwig Wolfram, The Roman Empire and Its Germanic Peoples », Archives de sciences sociales des religions [En ligne], 140 | octobre - décembre 2007, document 140-88, mis en ligne le 02 juillet 2008, consulté le 21 septembre 2020. URL : http://journals.openedition.org/assr/12233 ; DOI : https://doi.org/10.4000/assr.12233

Ce document a été généré automatiquement le 21 septembre 2020.

(C) Archives de sciences sociales des religions 


\section{Herwig Wolfram, The Roman Empire and Its Germanic Peoples}

Trad. de Thomas Dunlap. Berkeley -Los Angeles, University of California Press, 2005, $\mathrm{XX}+361 \mathrm{p}$.

\section{Rémi Gounelle}

1 Professeur émérite d'histoire médiévale à Vienne, Herwig Wolfram est un spécialiste bien connu du christianisme germanique. Son étude intitulée Das Reich und die Germanen, publiée à Berlin en 1990, est un classique. Une traduction anglaise en avait été publiée par University of California Press en 1997 ; elle est dorénavant disponible en format broché.

2 Le but poursuivi par Wolfram dans ce livre est explicitement formulé en ces termes: «(Le) sujet (de cet ouvrage) est la création, la durée et l'impact historique des royaumes que l'on appelle germaniques et qui ont à la fois transformé, dissous et prolongé l'Empire (romain) d'Occident » (p. 301). À travers cette phrase, que l'on aurait aimé lire avant le dernier chapitre du livre, apparaissent deux traits importants de la démarche de Wolfram, qui vont de pair: le point de vue adopté n'est pas romanocentré, et la rupture que marquerait la création des royaumes «barbares" est dédramatisée - l'auteur contestant notamment l'idée que les invasions des peuplades germaniques aient été la cause de la chute de l'Empire romain (pp. 191 sq.). Pour reprendre les termes de Wolfram : «L'apparition des peuplades germaniques, comme, après eux, des Slaves et des Arabes, ne doit pas être simplement appréhendée en termes de chute et de destruction; nous pouvons plutôt voir en elle la transformation assurément pénible - du monde romain et l'émergence de l'Europe du Haut Moyen Âge » (p. 193).

3 Après une introduction, trois chapitres dressent le décor: l'auteur discute les fondations de l'identité collective germanique, puis propose un panorama des relations entre l'Empire romain et les "barbares" aux $\mathrm{II}^{\mathrm{e}}$-III ${ }^{\mathrm{e}}$ siècles, avant de consacrer un chapitre aux «Peuplades germaniques à la fois ennemies et au service de l'Empire au $\mathrm{IV}^{\mathrm{e}}$ siècle ». Suit une présentation de l'«impérialisation des peuplades germaniques " (p. 110). Les sections qui suivent sont consacrées à chacun des royaumes qui se mettent 
en place : les Huns, le royaume de Toulouse (418-507), les Vandales en Afrique du Nord (406-534), en Italie Odoacre (476-493), puis Théodoric (451-526) - dont le règne est comparé à celui de Clovis (466/467-511) - et ses successeurs (jusqu'à Teja, en 552); l'auteur se tourne ensuite vers l'Angleterre des $\mathrm{V}^{\mathrm{e}}-\mathrm{VI}^{\mathrm{e}}$ siècles, puis vers les Burgondes (407/413-534), le royaume wisigothique d'Espagne (507/568-711/725), "première nation d'Europe » (p. 260) et les Lombards (488-643/652) - on notera l'absence des Francs, sinon à travers Clovis. Un chapitre conclusif, intitulé « La transformation du monde romain ", élargit la perspective.

D'une grande densité, et contenant d'amples informations sur des sujets peu connus de la plupart des historiens, l'exposé n'est pas de lecture aisée; l'auteur ne facilite d'ailleurs pas toujours la tâche de son lectorat, notamment en soignant peu les transitions entre les sections de son livre. Deux cartes, des chronologies et des généalogies sont toutefois là pour aider le lecteur.

5 Cette réédition a été, pour l'auteur, l'occasion de réviser ses vues sur un certain nombre de questions, en particulier dans le premier chapitre, et dans la section intitulée «Reconnaissance et intégration» (pp. 112-122), comme il le signale dans un postscript (p.13) - les pages concernant le christianisme auraient aussi mérité d'être revues (par exemple pp. 309 ss.). On peut regretter que la nature et la justification de ces modifications ne soient pas indiquées, ne serait-ce qu'en note; en l'état, le lecteur curieux d'identifier ces changements doit comparer les deux éditions... Dans les sections non revues, les maladresses de traduction, les fautes de grammaire et les erreurs typographiques relevées par les recenseurs du volume de 1997 n'ont malheureusement pas été corrigées. L'iconographie de l'original allemand n'a pas été rétablie. 